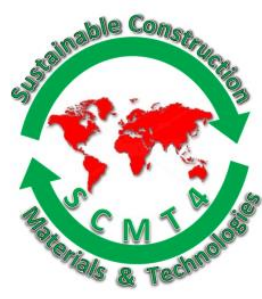

\title{
Assessment on the Sustainable Use of Alternative Construction Materials as a Substitute to Natural Aggregates
}

\author{
Theresa B. George ${ }^{1}$ and Joseph K. Anochie-Boateng ${ }^{2}$ \\ ${ }^{1}$ Transport Infrastructure Engineering; Council for Scientific and Industrial Research (CSIR) PO Box \\ 395, Pretoria, 0001, South Africa. Email: <tgeorge@csir.co.za >, \\ ${ }^{2}$ Transport Infrastructure Engineering; Council for Scientific and Industrial Research (CSIR) PO Box \\ 395, Pretoria, 0001, South Africa / Civil Engineering Department, Tshwane University of Technology, \\ Private Bag X680, Pretoria 0001 South Africa. Email: 〈janochieboateng@csir.co.za〉.
}

\begin{abstract}
South Africa is facing a potential shortage of virgin aggregates used to produce asphalt mixes for road construction. Although these aggregates have demonstrated the desired quality in asphalt mixes and have adhered to project specifications and performance criteria, there are, however, growing concerns regarding their future availability and sustainability. This paper discusses the potential risk of depletion of virgin aggregates that are utilised in typical asphalt mixes in South Africa, and identifies potential construction materials such as glass, slags and recycled asphalt pavement (RAP) that are locally available as alternative aggregate materials to virgin aggregates. An economic cost analysis conducted indicated that it is more cost-effective when using crushed glass for instance, as a substitute to virgin aggregate. Moreover, it was found that the use of crushed glass in asphalt mixes is both sustainable and feasible in South Africa. The findings presented in the paper are informative, emphasizing the need for the utilisation of alternative materials in order to address the depletion of traditional materials utilised in asphalt mix production in South Africa.
\end{abstract}

\section{INTRODUCTION}

The use of construction waste materials and industrial by-products (e.g. glass, slags, recycled asphalt pavement etc.) for road construction have recently been emphasised due to the potential depletion of high quality aggregate sources. Moreover, the need to utilise sustainable alternative materials is further stressed due to the ongoing fluctuations in road construction material prices (e.g. bitumen) as well as the increasing awareness regarding environmental matters such as disposals, green gas emissions etc. related to conventional asphalt materials.

Studies conducted by the Recycled Materials Resource Centre [RMRC, Madison, WI, USA] have revealed that reasonable performance has been observed when 10 to $15 \%$ of crushed glass is used to produce wearing surface mixes for asphalt pavements. However, quantities in excess of $15 \%$ can result in deterioration of the asphalt surfacing course due to stripping of the binder from the waste glass. In the late 1960s and early 1970s, glass asphalt pavements were implemented in the United States and Canada 
whereby test paving strips, during this time period, were located at almost 33 locations across the United States and Canada. There are currently numerous paving projects being carried out in the United States of which New York's Department of Transportation has utilised nearly 250,000 tons of glass for resurfacing applications between 1990 to 1995 [Wu et al. 1990]. In South Africa, a significant amount of processed glass in (in the form of fines) that cannot be used as re-cycled material during glass production accumulates as stockpiles. On average, 550,000 tons of waste glass finds its way into landfills every year, while only 200,000 tons of all glass containers (glass bottles and jars) is retrieved for recycling [Glass Recycling Company, 2010]. A substantial amount of waste glass is, therefore, available for exploitation in South Africa. However, up to now there have been few investigations on the application of waste glass in the field of pavement as well as in field applications in South Africa.

Industrial by-products such as steel and blast furnace slag are also commonly used in pavement applications internationally. Steel slag utilised in Singapore has out-performed typically used natural granite aggregate [Jones, 2000]. Steel slags are also more commonly used for road applications in Australia, due to stronger, better abrasion and impact resistance properties than blast furnace slags [Dippenaar 2004]. In addition, South Africa has a strong mineral based economy and is a leading world producer of both non-ferrous and ferrous metals. The presence of slag heaps is therefore widespread in South Africa. Air cooled blast furnace slag has been used for more than 30 years, albeit mostly as a G5 material (i.e. natural gravel with minimum CBR of $45 \%$ and PI value $<10$ according to the South African materials classification) [Paige Green 2008]. Steel slag has also recently been used as an aggregate in asphalt for the construction of a national route in South Africa.

The recycling of existing asphalt pavement also produces another alternative materials resulting in significant savings in material, money and energy. Although firm regulations stipulate between 5 and $50 \%$ of RAP utilisation to produce new asphalt mixtures [Mengqi et al. 2012], recent studies have revealed that RAP replacement at proportions greater than $50 \%$ is viable for production of new asphalt mixtures, leading to reasonable outcomes in the mechanical properties [Decker 1997], [Celauro 2010], [Reyes et al. 2012]. Further research in the utilisation of RAP is currently being carried out in various other countries whereby mixtures including 100\% RAP are presently being developed [Riebesehl 1993; Hossain et al. 1993; Harrington 2005].

The objective of the study being reported in this paper is to evaluate the availability and sustainability of virgin aggregates utilised in typical asphalt mixes in South Africa, and to identify locally available alternative construction materials that are cost-effective, sustainable and feasible, to be used as a substitute "aggregate" in asphalt mixes. This paper specifically focuses on crushed glass, slags and recycled asphalt pavement (RAP) as alternative substitute materials. An economic cost analysis for use of these materials is also evaluated in order to demonstrate the economic feasibility of these materials in comparison with virgin aggregates used in asphalt mixes.

\section{CURRENT SITUATION}

Virgin Aggregates and Sustainability. Due to the potential shortage of virgin aggregates used in asphalt mixes in South Africa, an assessment was performed on the availability and sustainability of aggregate materials. The goal is to alert the asphalt manufacturers and users on the possible depletion of virgin aggregate sources as well as to emphasise the need for alternative sources and possible recycling technology to be developed in order to meet aggregate demands for asphalt production in South Africa. The asphalt mixes selected for the study are typically used as wearing courses and have been constructed and tested on various trial sections in the province of Gauteng in South Africa. The aggregates were acquired from local quarries in close proximity to the asphalt plant. However, concerns about future supply of these aggregates as well as source depletion have not been considered thus far and consequently 
serves as part of the investigation that is reported in this paper. Information regarding future availability of the aggregates which are typically used in the asphalt mixes was attained from the respective quarries and indicated in Figure 1. It should be mentioned that due to sensitivity of the information only approximate figures were obtained. It was also agreed that the anonymity of the quarry names will be maintained.

Figure 1 illustrates the approximate productive life of specific aggregate quarries of which the respective aggregates are currently used for asphalt production in South Africa. There is a significant difference in the productive life of Quarries 4, 6 and 8 (averages about 5 to 10 years) when compared to the productive life of the other quarries which averages about 30 to 35 years. It can be observed that the mine sand reserves will only last for 5 years. "Quarry" 4 (a mining company) has, however, indicated that they have other sources of mine sand equating to 17 million tons of reserves that will last approximately 10 to 15 years. Even though this quantity may be sufficient for a short term period, it does signal the issue of mine sand availability after 15 years when compared with the presence of other aggregates after a period of 15 years. It was also found that the plant at Quarry 8 had recently shut down and a plant approximately 70 $\mathrm{km}$ north-west of the quarry is currently testing the application of quartzite materials for road construction. Thus, for now, the quartzite at the original quarry is not commercially available. The depletion of aggregates as well as the limitations experienced at the quarries necessitates the need to determine alternative sources of aggregates of adequate supply that are suitable for asphalt production.

An alternative solution that is more economical and environmentally friendly may be required whereby the virgin aggregates are replaced with alternative materials (i.e. waste materials and industrial byproducts) that will also meet the standard performance set for conventional aggregates in South Africa. Availability of the new materials (in quality and quantity) as well as costs that may be incurred through transport and or special manufacturing processes would also need to be taken into account when selecting a replacement "aggregate". Furthermore, sustainability of the aggregate or material sources identified should be compared with the sustainability of the existing aggregate sources which averages approximately 30 to 35 years.

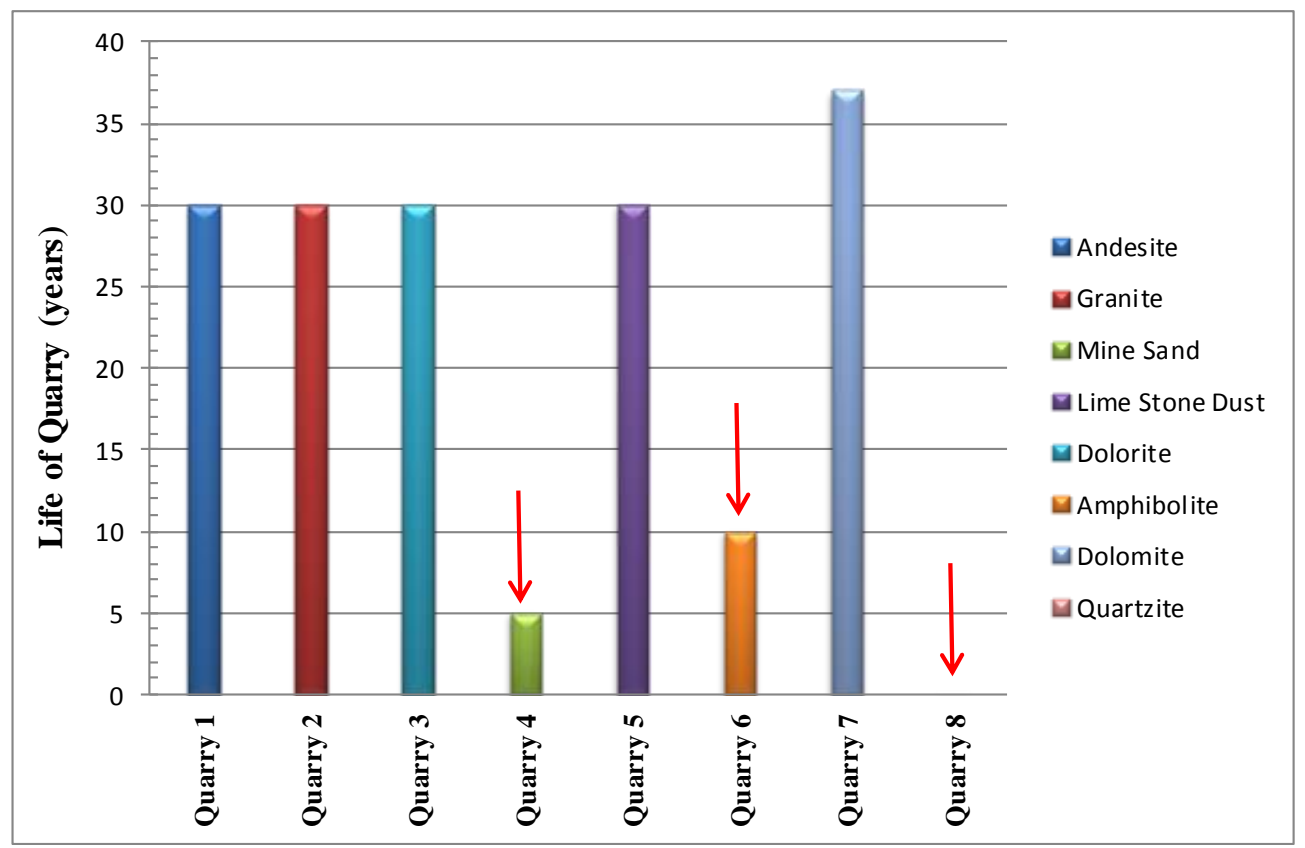

Figure 1. Life of Eight Aggregate Quarries in South Africa 


\section{Production Capacity of Plant Quarries}

Data on the approximate production capacity per month of each plant specific to each aggregate type and size relative to the South African asphalt mixes were also obtained from the plant quarries and are illustrated in Figure 2. The major asphalt manufacturing plant currently utilises between 15 and 25 thousand tonnes of aggregate per month. These figures can, therefore, be analysed by asphalt producers and users to determine production patterns and trends of a specific plant which can provide key stakeholders with an indication on the monthly availability of the aggregate type and size that may be required for a specific asphalt mix on a current or anticipated projects.

It should be taken into consideration that the information provided may vary significantly depending on the immediate aggregate material requirements, production rates per specific operational mode as well as daily consented hours which are subject to equipment availability, sales pressures etc. These factors would also prove valuable to key stakeholders during the planning and procurement stage of a road construction project.

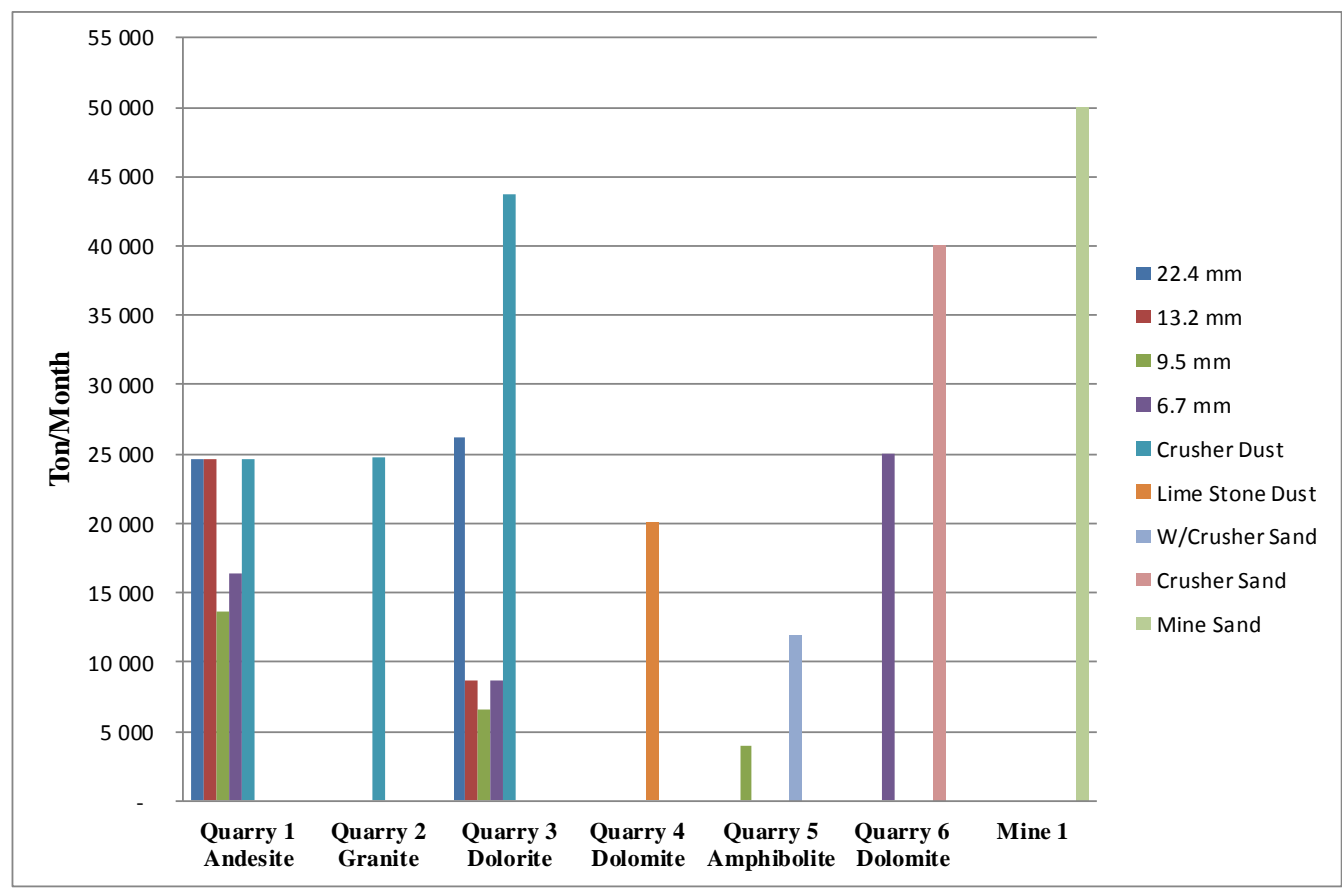

Figure 2. Plant Production Capacity per Month

\section{Construction Waste Materials}

\section{Waste Glass}

As mentioned in the introduction, there is a significant amount of waste glass deposited in landfill that is available for exploitation in South Africa. It is a matter of concern that the amount of waste glass placed in landfills is increasing and there is a likely scarcity of natural aggregate sources. Waste glass materials could be reclaimed and reprocessed into products which are useful, cost-effective, and sustainable for application in road construction.

During this study a major glass manufacturing company in South Africa, was identified as a sustainable source of waste glass. The company receives approximately 15,000 tons of waste glass per month. This is 
on average 180,000 tons every year. Of the 15,000 tons per month of waste glass collected for the manufacturing of glass containers, the company has indicated that approximately 3,000 tons per month of processed glass in the form of fines (i.e. less than $4.75 \mathrm{~mm}$ sieve size) that cannot be used as re-cycled material during glass production accumulates as stockpiles at the company's processing plant. According to the glass manufacturer, approximately R 1 million (approx. USD \$100,000) per month is accounted for the disposal and transportation of the waste glass to landfill sites. An alternative application can be proposed whereby the waste glass can be used as an "aggregate" substitution in road construction which will provide a more cost effective and environmentally friendly solution to disposal.

The discarded glass fines ranges between $4.75 \mathrm{~mm}$ and $0.075 \mathrm{~mm}$ and has a size distribution typical of fine granite aggregates. In addition, the glass fines were observed to be relatively free of contaminants such as paper, plastic, dirt debris as well as materials such as lead, arsenic, or similar toxic or hazardous metals, which present an attractive alternative to aggregates for use in road construction. The glass manufacturer has indicated that this material can be made available for commercial purposes, however, it was noted that the company only has one processing plant located in the Gauteng province. The location of the processing plant is within a maximum distance of $60 \mathrm{~km}$ to the major asphalt manufacturing plants in Gauteng. Transportation costs should therefore be taken into consideration should glass be considered as an alternative for implementation in road construction outside of Gauteng.

\section{Slags}

There are multiple producers of slag in the greater Gauteng area, which generates huge volumes of both iron and steel, and have major producers of ferrous alloys, chrome and platinum producers and manufacturers. In parallel, there are also multiple smaller scale iron and steel foundries besides the Scaw metals within the Gauteng region. Most of these establishments concentrate on smelting recycled and scrap iron, generating smaller volumes of slag which are subsequently handled through commercial waste disposal firms.

A radial zone of $100 \mathrm{~km}$ surrounding the major asphalt plants in the Gauteng province has been investigated. It was indicated, through correspondence with the above mentioned asphalt manufacturing plants, that a potential haul distance of about $100 \mathrm{~km}$ radius from any asphalt plant would most likely be economically viable Thus, primary metal smelting companies and associated producers of slag were identified within the zone earmarked, and included companies and firms dealing with zinc, titania, stainless steel, silico manganese, lead, iron and steel, ferrovanadium, ferromanganese and ferrochromium. Data was gleaned on the extent of slag reasonably expected to be produced by smelters through reviewing the public information available on their respective web portals, making specific enquiries and directly contacting the firms regarding the volume of slag they produced.

The majority of the ferrochromium companies indicated that there is plenty of slag available; however, attempts are currently being made to have their slag delisted as hazardous waste. The iron and steel companies also indicated that there is plenty of slag available of which some heaps consist of old slags. Some of the platinum companies indicated that their slag is discarded, sold or recirculated whereas two other platinum companies indicated plenty of available slag. The majority of zinc, titania, stainless steel and lead processing and manufacturing firms had no available stocks of slag since they had already transported their produce to toxic waste dumps.

\section{Reclaimed Asphalt Pavement (RAP)}

Reclaimed Asphalt Pavement (RAP) is generally a product of milling the asphalt layers within road pavements already in place. This is generally part of repairing existing pavements. If a project is marked out for repairs and rehabilitation and the existing asphalt layer is intended to be removed, there is potential 
to reuse the old asphalt in recycled asphalt mixes.

Considering that RAP is a key aspect with regard to recycling asphalt, it is important to ensure that consistent volumes of the product for the mixes are available. Thus, short term requirements can be generally fulfilled from stocks already present within the various asphalt plants which are in the process of recycling. It is therefore important to ensure that the available RAP is not squandered and scattered, but is instead stored properly and safely so that it can be utilized in the future within recycled asphalt mixes. National and provincial level re-modelling and rehabilitation projects entailing the removal of large amounts of asphalt, are considered a major source of RAP in the long run. Correspondingly, the volume of asphalt to be made available in this regard would significantly depend on the extent to which the asphalt is to be removed, as required in the rehabilitation design. In general, unless the as-built data is available and is in great detail, it is necessary to check quantities by taking core samples and measuring the width of the pavement.

It was indicated by a major asphalt manufacturing plant in the Gauteng province that processing capabilities range between $20 \%$ and $50 \%$ to recycle RAP in only four provinces in the country. Nevertheless, precise figures on the existing asphalt stocks within each of the processing sites were not disclosed, citing confidentiality issues. Furthermore, it should be noted that only around $20 \%$ of the existing road network within South Africa is currently paved.

\section{DISCUSSION ON ECONOMIC IMPACT ANALYSIS}

The decision of when or when not to use a waste or by-product material that is recovered for use in a pavement application (assuming that the material is capable of adequately performing in the proposed application) will in most cases depend on the cost of using the recovered material versus the cost of using virgin material. As a result, recovered materials must be cost- competitive with virgin materials for their utilization to be practical. A user guideline dealing with by-products and secondary use material for pavement construction, published by the [RMRC, Madison, WI, USA] recommended that there are three cost parameters that are of interest when evaluating the cost to be considered when using a recovered material in pavement applications. These are: (1) the cost of the material, (2) the cost of installation, and (3) the life-cycle cost of the pavement when using the material. Each of the three costs could be relevant when evaluating the potential cost-benefits of using a recovered material.

\section{Cost of Material}

The cost of material includes, but is not limited to, the cost that the purchaser would pay to have the material delivered to the asphalt production plant or project site. The cost of material can then be identified as the delivered price $\left(\mathrm{C}_{\mathrm{DP}}\right)$. Equation 1 shows the delivered price as the accumulated sum of the price of the raw material $\left(\mathrm{P}_{\mathrm{RM}}\right)$, cost of processing $\left(\mathrm{C}_{\mathrm{PR}}\right)$, cost of stockpiling $\left(\mathrm{C}_{\mathrm{ST}}\right)$, cost of loading $\left(\mathrm{C}_{\mathrm{LD}}\right)$, cost of transporting $\left(\mathrm{C}_{\mathrm{TR}}\right)$, and profit $(\mathrm{P})$ [RMRC, Madison, WI, USA].

$\mathrm{C}_{\mathrm{DP}}=\mathrm{P}_{\mathrm{RM}}+\mathrm{C}_{\mathrm{PR}}+\mathrm{C}_{\mathrm{ST}}+\mathrm{C}_{\mathrm{LD}}+\mathrm{C}_{\mathrm{TR}}+\mathrm{P}$

\section{Waste Glass}

It is relevant to take into consideration that the waste glass provided by the above mentioned glass manufacturing company is free of cost since charging for the same would entail the firm paying a waste disposal fee. Thus, the waste glass has a nil $\mathrm{P}_{\mathrm{RM}}$ value. Accordingly, the $\mathrm{C}_{\mathrm{PR}}$ of waste glass is zero since the wastage is accumulated as a by-product of the glass container manufacturing process. This is so since all crushed glass smaller than $5 \mathrm{~mm}$ are discarded and considered a waste which is excluded from the 
mainline manufacturing process and set aside. The $\mathrm{C}_{\text {ST }}$ has minimal cost factors in consideration of the fact that the crushed glass less than $5 \mathrm{~mm}$ are routed through a specific chute within the conveyer system and is collected in a $4 \mathrm{~m}$ by $4 \mathrm{~m}$ stockpile area. Thus, the cost incurred in hiring the labour for loading and unloading the wastage, i.e. the $\mathrm{C}_{\mathrm{LD}}$ in conjunction with the $\mathrm{C}_{\mathrm{TR}}$, which is a function of the distance the crushed glass needs to be transported, are considered to be the only worthwhile costs incurred in the case of acquiring waste glass from the glass manufacturing company. A distance of $60 \mathrm{~km}$ at a rate of $\mathrm{R} 1.10$ ( $1 \mathrm{USD} \approx \mathrm{R} 10$ ) per ton per $\mathrm{km}$ is factored in to be covered from the manufacturing site of the glass to the asphalt plants with the assumption that the project sites are in close proximity to the asphalt plants. In the event that this distance exceeds $60 \mathrm{~km}$, there could be corresponding increases in the transportation costs. In addition, the profit element is not included within the cost of the material, since this is considered a variable which would differ in relation to multiple clients.

\section{Slags}

A typical steel production plant, located within a $100 \mathrm{~km}$ radial zone of the asphalt manufacturing plants provided the indicative cost of the material, exclusive of the $\mathrm{C}_{\mathrm{TR}}$. Consequently, the cost of the material is inclusive of the $\mathrm{C}_{\mathrm{LD}}, \mathrm{C}_{\mathrm{ST}}, \mathrm{C}_{\mathrm{PR}}$ and the $\mathrm{P}_{\mathrm{RM}}$ as indicated in Table 1 . The $\mathrm{C}_{\mathrm{TR}}$ was factored in at a rate of R1.30 per ton per kilometre. The transportation cost is more pronounced in the case of steel slag in consideration of the higher specific gravity in comparison to that of virgin material. This higher specific gravity factor would also impact the volume of steel slag required for paving a road construction project in comparison to the volumes of virgin material for an equal length of road. Thus, more quantities of bitumen would also be required in the asphalt mix in consideration of the greater weight of the steel slag. These factors are major reasons contributing to the implementation of steel slag being more costly than virgin aggregates.

The distance from the steel plant to the asphalt plants is also assumed to be approximately $60 \mathrm{~km}$ in order to make an equal comparison and avoid variances in costs incurred by distance. This is also under the assumption that the project sites are in close proximity to the asphalt plants. It should therefore be factored in that should the distance be greater than the $60 \mathrm{~km}$ assumed, additional transportation costs would be incurred. Profits were not included in the cost of the material as it was indicated that the profits may differ from in relation to multiple clients.

\section{RAP}

The aggregate RAP cost parameters could significantly vary in consideration of the source utilized. Thus, the same could be millings provided from road repair, rehabilitation projects etc. Further, there would be variations in the distances involved in transporting the milling from various project sites to the asphalt manufacturing plants, contributing to major variations in the $C_{T R}$ values. Furthermore, the $P_{R M}$ of $R A P$ can either be charged at a cost or can be obtained for free. For the purpose of the study, it is assumed that the millings are obtained for free and is brought in from a project site $60 \mathrm{~km}$ from the asphalt plant. The $\mathrm{C}_{\mathrm{LD}}$ the material and transporting it at a rate of R1.30 per ton per kilometre from the project site to the asphalt plant forms part of the total cost of the material. As previously mentioned, the asphalt plants have varying processing capabilities as well and hence the $\mathrm{C}_{\mathrm{PR}}$ varies from plant to plant. The entire procedure would entail milling the RAP and ensuring the transportation of the same to the asphalt plant, its crushing and then screening the same while the RAP is loaded and taken to the stockpile area. The $\mathrm{C}_{\mathrm{PR}}$ has been obtained from the asphalt plant with the highest processing capability. The $\mathrm{C}_{\mathrm{ST}}$ can also vary significantly from one plant to the other based on storage capacity. However, the $\mathrm{C}_{\mathrm{ST}}$ at the plant that processes the most RAP was taken into account and is considered zero due to sufficient storage capacity at the plant. 


\section{Virgin Aggregates}

As part of this study, the cost of andesite, granite and mine sand virgin aggregates, widely utilized in dense-graded asphalt mixes as wearing courses, were evaluated. The objective was to draw a cost comparison with the above construction waste materials. The associated cost of the various aggregates excludes the $\mathrm{C}_{T R}$ which was provided by the specific quarries. Thus, the $\mathrm{C}_{\mathrm{LD}}, \mathrm{C}_{\mathrm{ST}}, \mathrm{C}_{\mathrm{PR}}$ and the $\mathrm{P}_{\mathrm{RM}}$ are inclusive within the material cost provided, with the $\mathrm{C}_{\mathrm{TR}}$. indicated to be at a rate of $\mathrm{R} 1.30$ per ton per kilometre.

\section{Cost of Installation}

Equation 2 shows the net installation cost $\left(\mathrm{C}_{\mathrm{I}}\right)$, which is considered to be inclusive of the testing and inspection expense $\left(\mathrm{T}_{\mathrm{RP}}\right)$, the construction cost $\left(\mathrm{C}_{\mathrm{C}}\right)$ and the design cum application costs $\left(\mathrm{C}_{\mathrm{DR}}\right)$ [RMRC, Madison, WI, USA]. The time and effort involved in the design when using alternative and virgin materials $\left(\mathrm{C}_{\mathrm{DR}}\right)$ have been considered the same. Furthermore, through correspondence with key personnel in the road construction industry, it has been indicated that the construction procedures for paving asphalt surfaces are the same regardless of the type of materials used to manufacture the asphalt. This ensures that the $\mathrm{C}_{\mathrm{C}}$ remains the same for both alternative as well as virgin materials. The degree of testing and field inspection requirements $\left(\mathrm{T}_{\mathrm{RP}}\right)$ compared with that ordinarily required for the same application using virgin material have also been indicated to be minimal. However, prior to the manufacturing of asphalt mixes containing RAP, standard tests such as penetration, softening point as well as recovery of the binder and aggregates is required. It should be noted that although this will not have a cost implication on the $\mathrm{C}_{\mathrm{I}}$, this will however increase the $\mathrm{C}_{\mathrm{DP}}$ of the RAP.

$\mathrm{C}_{\mathrm{I}}=\mathrm{C}_{\mathrm{DR}}+\mathrm{C}_{\mathrm{C}}+\mathrm{T}_{\mathrm{RP}}$

\section{Life-Cycle Cost}

Should there be significant variations observed with regard to either the annual maintenance costs or the length of product life of the asphalt pavement, a related life-cycle cost analysis (LCCA) enables calculating a cost-benefit comparison in relation to the alternative and virgin material used in road construction [RMRC, Madison, WI, USA]. This methodology is attributed to RMRC and is reflective of multiple life-cycle cost calculations and approaches used to quantify the annual effective cost ( $\mathrm{A}_{\mathrm{EC}}$ ) resulting from the application of the respective aggregates. Equation 3 shows the methodology related to calculating the $\mathrm{A}_{\mathrm{EC}}$ value, and is inclusive of the annual maintenance cost $\left(\mathrm{C}_{\mathrm{AM}}\right)$ along with the corresponding installation cost. The related capital recovery factor (CRF) is considered to be a function of the fixed interest rate (i) and the related product life of the asphalt pavement (n), calculated in terms of the number of years. The CRF calculated is stated in Equation 4, and assumes an $8 \%$ interest rate in relation to $\mathrm{i}$, while the life of the asphalt pavement is assumed to be around 20 years while using both alternative and virgin material. The CRF for the alternative and virgin materials were calculated as $\mathrm{R} 0.10$ per ton of aggregate. Furthermore, routine annual maintenance costs $\left(\mathrm{C}_{\mathrm{AM}}\right)$ for an asphalt pavement that comprises of glass, steel and RAP was indicated, by personnel in the road construction industry, as approximately the same as an asphalt pavement comprising of virgin aggregates for medium to heavy traffic loads. Correspondingly, it is concluded, that there is minimal variance in the calculated $A_{\mathrm{EC}}$ for an asphalt pavement using alternative materials to a conventional asphalt pavement.

$$
\begin{aligned}
& A_{E C}=C_{I} *(C R F)+C_{A M} \\
& C R F=\left(i(1+i)^{n}\right) /\left((1+i)^{n}-1\right)
\end{aligned}
$$


Table 1 demonstrates the cost comparison between the alternative construction materials chosen for the study (waste glass, steel slag and RAP) and typically used virgin aggregates in asphalt mixes within the defined cost categories.

Table 1. Cost Per Ton Comparison of Virgin Materials and Alternative Construction Materials

\begin{tabular}{|c|c|c|c|c|c|}
\hline \multicolumn{6}{|c|}{ Alternative Materials } \\
\hline & & Glass & \multicolumn{2}{|l|}{ Slag } & RAP \\
\hline \multicolumn{2}{|l|}{ Delivered Price $\left(\mathrm{CDP}_{\mathrm{DP}}\right)$} & R 200.00 & \multicolumn{2}{|l|}{ R 300.00 } & R 270.00 + *Testing \\
\hline \multicolumn{2}{|c|}{ Price of Raw Material $\left(\mathrm{P}_{\mathrm{RM}}\right)$} & R 0.00 & \multicolumn{2}{|l|}{ R 140.00} & R 0.00 \\
\hline \multicolumn{2}{|c|}{ Cost of Processing the Material $\left(\mathrm{C}_{\mathrm{PR}}\right)$} & R 0.00 & Included in $\mathrm{P}_{\mathrm{RM}}$ & & R $90.00+*$ Testing \\
\hline \multicolumn{2}{|c|}{ Cost of Stockpiling the Material ( $\left.\mathrm{C}_{\mathrm{ST}}\right)$} & $\mathrm{R} 0.00$ & Included in $\mathrm{P}_{\mathrm{F}}$ & & R 0.00 \\
\hline \multicolumn{2}{|c|}{ Cost of Loading the Material $\left(\mathrm{C}_{\mathrm{LD}}\right)$} & R 70.00 & \multicolumn{2}{|c|}{ Included in $\mathrm{P}_{\mathrm{RM}}$} & \\
\hline \multicolumn{2}{|c|}{$\begin{array}{l}\text { Cost of Transporting the Material } \\
\left(\mathrm{C}_{\mathrm{TR}}\right)\end{array}$} & R130.00 & \multicolumn{2}{|l|}{ R 160.00} & $\begin{array}{l}\mathrm{K} 20.00 \\
\mathrm{R} 160.00\end{array}$ \\
\hline \multicolumn{6}{|c|}{ Virgin Materials } \\
\hline & $\begin{array}{l}\text { Andesite } \\
(9.5 \mathrm{~mm})\end{array}$ & $\begin{array}{l}\text { Andesite } \\
(6.7 \mathrm{~mm})\end{array}$ & $\begin{array}{c}\text { Andesite } \\
\text { (Crusher Dust) }\end{array}$ & $\begin{array}{c}\text { Granite } \\
\text { (Crusher Sand) }\end{array}$ & Mine Sand \\
\hline Delivered Price (CDP) & R 200.00 & R 200.00 & R 225.00 & R 210.00 & R 210.00 \\
\hline $\begin{array}{l}\text { Price of Raw Material } \\
\left(\mathrm{P}_{\mathrm{RM}}\right)\end{array}$ & R 170.00 & R 170.00 & R 195.00 & R 180.00 & R 180.00 \\
\hline $\begin{array}{l}\text { Cost of Processing the } \\
\text { Material }\left(\mathrm{C}_{\mathrm{PR}}\right)\end{array}$ & $\begin{array}{l}\text { Included in } \\
P_{R M}\end{array}$ & $\begin{array}{l}\text { Included in } \\
\mathrm{P}_{\mathrm{RM}}\end{array}$ & $\begin{array}{l}\text { Included in } \\
P_{R M}\end{array}$ & $\begin{array}{l}\text { Included in } \\
\mathrm{P}_{\mathrm{RM}}\end{array}$ & $\begin{array}{l}\text { Included in } \\
P_{R M}\end{array}$ \\
\hline $\begin{array}{l}\text { Cost of Stockpiling the } \\
\text { Material (CST) }\end{array}$ & $\begin{array}{l}\text { Included in } \\
\mathrm{P}_{\mathrm{RM}}\end{array}$ & $\begin{array}{l}\text { Included in } \\
\mathrm{P}_{\mathrm{RM}}\end{array}$ & $\begin{array}{l}\text { Included in } \\
\mathrm{P}_{\mathrm{RM}}\end{array}$ & $\begin{array}{l}\text { Included in } \\
\mathrm{P}_{\mathrm{RM}}\end{array}$ & $\begin{array}{l}\text { Included in } \\
\mathrm{P}_{\mathrm{RM}}\end{array}$ \\
\hline $\begin{array}{l}\text { Cost of Loading the } \\
\text { Material }\left(\mathrm{C}_{\mathrm{LD}}\right)\end{array}$ & $\begin{array}{l}\text { Included in } \\
\mathrm{P}_{\mathrm{RM}}\end{array}$ & $\begin{array}{l}\text { Included in } \\
\mathrm{P}_{\mathrm{RM}}\end{array}$ & $\begin{array}{l}\text { Included in } \\
\mathrm{P}_{\mathrm{RM}}\end{array}$ & $\begin{array}{l}\text { Included in } \\
\mathrm{P}_{\mathrm{RM}} \\
\end{array}$ & $\begin{array}{l}\text { Included in } \\
\mathrm{P}_{\mathrm{RM}}\end{array}$ \\
\hline $\begin{array}{l}\text { Cost of Transporting the } \\
\text { Material }\left(\mathrm{C}_{\mathrm{TR}}\right)\end{array}$ & R 30.00 & R 30.00 & R 30.00 & R 30.00 & R 30.00 \\
\hline
\end{tabular}

*Cost of additional testing prior to processing (binder recovery, penetration and softening point)

\section{SUMMARY AND CONCLUSION}

This paper demonstrated that irrespective of the type of material utilized for construction, aspects related to installation and maintenance costs remain the same, reflecting minimal impact on the life cycle cost of the asphalt roads. This would be the case provided that the design life of the pavement is the same while using both alternative and virgin materials. Sources of alternative construction materials i.e. waste glass, slags and RAP have been identified in the Gauteng province of South Africa and is deemed sustainable for the application as an "aggregate" substitute in asphalt mixes. In comparison, the use of waste glass in asphalt was found to be more economically sustainable and feasible than steel slag and recycled asphalt (RAP) as the total cost of the slag and RAP was estimated to be approximately R 90.00 per ton more costly than the virgin aggregates. Using waste glass as a replacement for virgin aggregates could reduce the total cost of materials by approximately, R 10.00 per ton. This study concludes that the cost of transporting construction waste materials is a major factor in assessing their feasibility for future use in asphalt production. For instance, the economic impact analysis conducted on the alternative materials investigated indicates that the use of waste glass is economically feasible as long as the transportation distance is limited to within a radius of $100 \mathrm{~km}$ from the asphalt production plant. 


\section{ACKNOWLEDGEMENT}

Funding for this study was provided through the Parliamentary Grant by the CSIR. The authors would also like to acknowledge the support provided by Consol for providing the waste glass material.

\section{REFERENCES}

Celauro, C., Bernado, C. and Gabriele, B. (2010). Production of innovative, recycled and highperformance asphalt for road pavements. Resource Conservation Recycling, 54(6), pp.337-347.

Decker, D. (1997). State of the practice for use of RAP in hot mix asphalt. Journal of the Association of Asphalt Paving Technologists, 66(704).

Deppenaar, R. (2004). Industrial uses of slag - the use and re-use of iron and steelmaking slags. In: Proc VII International Conference on Molten Slags, Fluxes and Salts.

Harrington, J. (2005). Recycled Roadways. Public Roads, 68(4), pp.30-37.

Hossain, M., Metcalf, D. and Scofield, L. (1993). Performance of recycled asphalt concrete overlays in Southwestern Arizona. Transportation Research Board, (1427), pp.20-37.

Jones, NC. 2000. The use of EAF slag as aggregate in asphalt. MultiServ, United Kingdom.

Mengqi, W., Haifang, W., Muhunthan, B. and Kalehiwot, N. (2012). Influence of RAP content on the air void distribution, permeability and moduli of the base layer in recycled asphalt pavements. In: TRB 91st annual meeting. TRB.Nash, P., Jayawickrama, P., Tock, R., Senadheera, S., Viswanathan, K. and Woolverton, B. (2015). Use of Glass Cullet in Roadway Construction. Research Report Number 01331-1. Texas, USA: College of Engineering Texas Tech University, pp.1-13.

Paige-Green, P. (2008). Feasibility Study on the Use of Slags in Asphalt. Pretoria, South Africa: CSIR, pp.3-13.

Riebesehl, G. and Nolting, M. (2009). Unlocking the full technical potential of RAP. In: Petersen Asphalt Research Conference, Laramie, USA.

Rmrc.wisc.edu, (2015). UG-EG-Cost Issues | Recycled Materials Resource Center. [online] Available at: http://rmrc.wisc.edu/ug-cost-issues/ [Accessed 15 Nov. 2015].

Theglassrecyclingcompany.co.za, (2015). The Glass Recycling Company | Glass Recycling in South Africa. [online] Available at: http://www.theglassrecyclingcompany.co.za/ [Accessed 15 Nov. 2015].

Wu, S., Yang, W. and Xue, (1990). Preparation and Properties of Glass-asphalt Concrete. Wuhan, China: Wuhan University of Technology. 